Paulo da Silva Quadros

\title{
EPISTEMOLOGIA DA LEITURA: UM CAMPO INTERPRETATIVO DE INSERÇÃO DOS MEIOS DIGITAIS NO CONTEXTO ESCOLAR
}

Tese apresentada à Comissão de Pós-graduação da Faculdade de Educação da Universidade de São Paulo (ECA/USP), como exigência parcial para obtenção do título de DOUTOR em Didática, sob a Orientação da Profa. Dra. Stela C. B. Piconez.

\section{UNIVERSIDADE DE SÃO PAULO}

Faculdade de Educação 
Eu, Paulo da Silva Quadros, autorizo a reprodução e divulgação total ou parcial deste trabalho, por qualquer meio convencional ou eletrônico, para fins de estudo e pesquisa, desde que citada a fonte.

371.369 Quadros, Paulo da Silva.

Q1e Epistemologia da leitura : um campo interpretativo de inserção dos meios digitais no contexto escolar / Paulo da Silva Quadros; orientação Stela C. Bertholo Piconez. São Paulo: s.n., 2009. 468 p: il.

Tese (Doutorado - Programa de Pós-Graduação em Educação. Área de Concentração: Didática) - - Faculdade de Educação da Universidade de São Paulo.

1. Tecnologia da informação 2. Tecnologia - Educação 3. Formação de professores 4. Rede de comunicação 5. Leitura - Teoria 6. Epistemologia 7. Hermenêutica 8. Cognição 9. Educação escolar 10. Didática, Stela C. Bertholo, orientador.

CDU: 371.369 


\section{Banca Examinadora}

Profa. Dra. Stela C. B. Piconez 



\section{In Memoriam}

Dê e Lú

Idéia Mãe, Sentimento Pai - o diálogo entre a racionalidade sensível e o sentimento racional agora repousam em mim para sempre em cada passo do reinventar a vida e do prosseguir continuamente em minha jornada do conhecimento. Não sei, nada sei, sou um quase nada pelo pouco que um dia ainda haverei de saber...

Sou um homem comum

Qualquer um

Enganando entre a dor e o prazer

Hei de viver e morrer

Como um homem comum

Mas o meu coração de poeta

Projeta-me em tal solidão

Que às vezes assisto

A guerras e festas imensas

Sei voar e tenho as fibras tensas

E sou um

Ninguém é comum

E eu sou ninguém

No meio de tanta gente

De repente vem

Mesmo eu no meu automóvel

No trânsito vem

O profundo silêncio

Da música límpida de Peter Gast

Escuto a música silenciosa de Peter Gast

Peter Gast

O hóspede do profeta sem morada

O menino bonito Peter Gast

Rosa do crepúsculo de Veneza

Mesmo aqui no samba-canção

Do meu rock'n'roll

Escuto a música silenciosa de Peter Gast

Sou um homem comum

Peter Gast (letra e música de Caetano Veloso) 


\section{AGRADECIMENTOS AOS MESTRES}

À Prof. Stela C. B. Piconez, pela inestimável oportunidade dada à consecução deste trabalho científico provocativo e inquietador, e à sua habilidade inequívoca de ver para além do aparentemente visível.

Ao Prof. Osvaldo Sangiorgi, meu mestre primeiro nos ensinamentos de ciência e vida cotidiana.

Ao Prof. Ciro Marcondes, pela acolhida generosa em seu espaço de saber filosófico e oficina de invariáveis indagações perceptivas.

A Mr. James Burke, mestre de muitos mestres, a quem saúdo pela sua generosidade inefável, sem a qual não seria possível a realização deste trabalho intelectual e suas proposições indagativas.

Ao Prof. Nilson J. Machado, pelos seus ensinamentos sempre valiosos em minhas andanças intelectuais e pelo irrecusável convite aos vários cafés filosóficos por vir.

Ao Prof. Marcos Ferreira dos Santos, pelos cordiais ensinamentos antropológicos da vastidão crepuscular de mitos e símbolos que povoam a complexidade da cultura humana.

À Profa. Lucilene Cury, a quem agradeço imensamente pelo apreço às lutas travadas em favor do exercício do meu intelecto "underground".

À Profa. Cremilda Medina, pelas recepções sempre cordiais e respeitosas ao propósito de meus estudos intelectuais.

Finalmente, à lembrança de Hugo Assmann, educador e epistemólogo em didática, com quem não foi possível ter um contato mais estreito, mas de quem os livros são em si o alicerce fecundo no caminho para muitas indagações pedagógicas frutíferas. 


\section{Amigos ou tesouros escondidos? Palavras nunca serão suficientemente expressivas para abarcar o infinitamente inexprimível diante de todas elas...}

Abençoados os que possuem amigos, os que os têm sem pedir.

Porque amigo não se pede, não se compra, nem se vende.

Amigo a gente sente!

Poema "Bons Amigos", de Machado de Assis.

À minha maninha Lã: a jóia dos pais e o tesouro dos amigos. Um grande aprendizado do olhar feminino ao longo da vida, que me alimenta de inquietações assustadoramente irremediáveis.

Ao Fernando: companheiro nosso dos doces e amargos perigos da vida - ideais, contestações e inquietudes infindáveis.

Ao incansável Samuel: nosso irmão de coração e "grand" camarada em alta cultura e sabedoria popular. Um festival de conhecimentos rumo ao mundo do desconhecido.

Aos inestimáveis amigos Marcelo e Humberto, companheiros de bares, cervejas e raras vivências com gloriosas inquietações.

À Cici: nossa mãe adotiva por razão de sentimento e sentido de razão.

À Valéria, grande amiga de batalhas gloriosas nos percursos da pós brasileira, sem qualquer redenção.

À Janina: uma alma paulistana em profusão, que sonha por habitar o mundo de lirismo poético concreto, pós-concreto, pós-tudo.

Ao Dario e Regina, amigos com os quais se descobre a arte do querer bem.

À Rose (Rock): amiga de sempre nas minhas reviravoltas intelectuais e itinerários musicológicos. 
Desejo também expressar meus agradecimentos aos seguintes Grupos de Pesquisa da Universidade de São Paulo:

Grupo Alpha da Faculdade de Educação da USP, sob a coordenação científica da Profa. Stela. Foram inestimáveis os vislumbres intelectuais compartilhados com colegas notáveis: Silvana, Mauro, Marcelo, Wanderlucy, Cristina, Josette, Lucy, Cibele e Edvane.

FiloCom - Grupo de Estudos em Filosofia da Comunicação da Escola de Comunicações e Artes da USP, sob a coordenação científica do Prof. Ciro Marcondes. Foram realizadas muitas discussões em torno de achados e redescobrimentos intelectuais. Um agradecimento especial à acolhida afetiva sem precedentes dos pesquisadores do Núcleo José Reis de divulgação científica, da ECA/USP, também coordenado pelo Prof. Ciro, a saber: Glória, Osnir e Prof. Crodow aldo Pavan.

Laboratório de Linguagens Digitais (LDD) do Grupo de Cibernética Pedagógica da ECA/USP, sob coordenação da Prof. Lucilene Cury. Foram realizados encontros e discussões com as quais este trabalho foi percebido com significativo vínculo conceitual.

\section{E o que falar do Amor, quando as palavras não bastam e são apenas articulações inúteis para expressar seu real sentido? Há sentido sem amor assim como amor sem sentido?}

À Rê, minha companheira e cúmplice de afetos e amorosidades: uma luz resplandecente em meu horizonte desbravador por alegrias imanentes e transcendentais.

\section{Financiamento da Pesquisa}

Por último, à Agência Capes pelo apoio financeiro valioso e indispensável à consecução deste estudo. 


\section{$\underline{\text { RESUMO }}$}

A idéia de uma epistemologia da leitura remete essencialmente ao momento contemporâneo da morfogênese do conhecimento humano permeado por múltiplas interfaces conceituais que desfronteirizam áreas disciplinares do saber, consideradas habitualmente rígidas e particionadas. Dentro desta visão transformacional de leitura, hipertextualidade, interconectividade e transversalidade, por exemplo, constituem-se em elementos co-restruturantes na interpretação de novas realidades que redimensionam o pensamento humano.

No campo da educação e da didática contemporâneas, considerando-se a interface entre educação e comunicação, para se compreender as mediações que ocorrem na mídia digital interativa, o trabalho visa investigar como a epistemologia da leitura pode representar um campo interpretativo que possibilite a inserção dos meios digitais dentro do contexto escolar.

Para tal, o estudo defende teoricamente a inter-relação conceitual indissociável entre midiologia, educação e hermenêutica na era das redes digitais para fundamentar as necessidades de mudanças dos referenciais interpretativos dos professores no espaço escolar frente a um cenário pedagógico cada vez mais dinâmico.

Já de um ponto de vista mais ilustrativo, o estudo contextualiza em termos práticos, a interface entre tecnologias digitais, mediações e processos interpretativos do conhecimento, servindo-se de casos ilustrativos. Por exemplo, a partir das interconexões conceituais entre o pensamento de Jacob Bronowski e James Burke. E por meio de comparações entre experiências realizadas pelo Instituto James Burke (projeto k-web) e o Núcleo de Educação de Jovens e Adultos da Faculdade de Educação da USP (NEAFE/USP), com destaque para o Sistema Transversal de Ensino e Aprendizagem (STEA).

Palavras-chave: midiologia, formação de professores, tecnologias de informação e comunicação, conhecimento como rede, ciências cognitivas, hermenêutica. 


\section{$\underline{\text { SUMARIO }}$}

La idea de una epistemología de la lectura remetí esencialmente al momento contemporáneo del la morfogenesis del lo conocimiento humano permeado por múltiplas interfaces conceptuals que desfronterizan áreas disciplinarias del saber, consideradas asiduamente rígidas y fragmentadas. A partir de este entendimiento transformativo del la lectura, hipertextualidad, interconectividad y transversalidad, por ejemplo, constituyen elementos co-reestructurantes en la interpretación del las nuevas realidades que dimensionan lo pensamiento humano.

En lo campo de la educación y didáctica contemporáneas, considerando la interface entre la educación y comunicación, para comprenderse las mediaciones que acontecen in la media digital interactiva, lo estudio investiga el modo la epistemología de la lectura representa un campo interpretativo que posibilite una inserción de los medios digitales en lo contexto escolar.

En este aspecto, lo estudio considera teóricamente la interrelación conceptual indisociable entre midiología, educación y hermenéutica in la era de las redes digitales para fundamentar las necesidades de mudanzas de los referenciales interpretativos de los profesores en lo espacio escolar ante a un escenario pedagógico cada vez más dinámico.

Con relación a un punto de vista más ilustrativo y en términos prácticos, lo estudio contextualiza la interface entre tecnologías digitales, mediaciones y procesos interpretativos de lo conocimiento, mostrando casos que ejemplifican lo enfoque empleado. Por ejemplo, a partir de las interconexiones entre lo pensamiento de Jacob Bronowski y James Burke. Y por medio de comparaciones entre experiencias realizadas por lo Instituto James Burke (projeto K-Web) y lo Núcleo de Educación de Jóvenes y Adultos de la Facultad de Educación de la Universidad de São Paulo (NEA-FE/USP), con destaque para lo Sistema Transversal de Enseñanza y Aprendizaje (STEA).

Palabras clave: midiología, formación de profesores, tecnologías de información y comunicación, conocimiento como rede, ciencias cognitivas, hermeneutica. 


\section{Lista de Figuras Ilustrativas}

\section{Capítulo 5}

Figura 1 - Múltiplos conceitos de Mediação, pág. 178.

Figura 2 - Descrição do fórum sobre Mediações, pág. 208.

\section{Capitulo 6}

Figura 3 - Cópia da página 22 do livro "Teia do Conhecimento”, de James Burke, pág. 236.

Figura 4 - Cópia da página 262 do livro “Teia do Conhecimento”, de James Burke, pág. 237.

Figura 5 - Apresentação das ferramentas navegacionais do jogo “Conexões”, pág. 240.

Figura 6 - Seqüência de ícones que representam a cadeia de conexões entre vários inventos, pág. 241.

Figura 7 - Imagem do portal do projeto K-Web, pág. 250.

Figura 8 - Modelo de Fichas Temáticas do STEA, contendo campos de articulações, pág. 258.

Figura 9 - Exemplo de folha-anexa do STEA, pág. 263.

Figura 10 - Modelo de folha-tarefa do STEA, pág. 264.

Figura 11 - Apresentação do portal do NEA/FE-USP (www.nea.fe.usp.br), pág. 265.

Figura 12 - Descrição das estratégias das atividades propostas pelo Grupo Alpha de pesquisa, pág. 269.

Figura 13 - Descrição das estratégias de estudos e pesquisas do Grupo Alpha, pág. 270.

Figura 14 - Atual configuração do ambiente moodle para uso do Grupo Alpha, pág. 271. 
Figura 15 - Amostra de uso do software TheBrain em site científico, pág. 275.

Figura 16: Mapa conceitual do K-Web, pág. 276.

Figura 17: Protótipo do $K$-Web, representado com outros detalhamentos conceituais, pág. 277.

Figura 18 - Estrutura da Ficha Temática do STEA remodelada no TheBrain, pág. 279.

Figura 19 - Estrutura do glossário de Assmann, remodelada no TheBrain, pág. 283. 


\section{sumário}

\section{RESUMO}

APRESENTAÇÃO

INTRODUÇÃO

TRAJETÓRIA METODOLÓGICA 23

A - Contexto Histórico da Teoria Hermenêutica 24

B - Contexto da Hermenêutica em relação ao foco da pesquisa 49

C -Tratamento Metodológico da Pesquisa

CAPÍTULO I

DAS CONCEPÇÕES DE LEITURA,

EPISTEMOLOGIA DA LEITURA E PROCESSOS

MEDIATIVOS

1.1 Da leitura da Natureza à Natureza da Leitura $\quad 71$

1.2 Da Leitura do Mundo ao Mundo da Leitura $\quad 75$

1.3 Leitura e sensibilidades $\quad \mathbf{8 4}$

1.4 Rumo a uma Epistemologia da Leitura $\quad 89$

CAPÍTULO II 101

PRESSUPOSTOS MIDIOLÓGICOS: DAS

CONCEPÇÕES DE MEIOS, MÍDIAS E 


\section{MEDIAÇÕES}

2.1 Meios, Mídias e Mediações: Breve Postulado 102

2.2 Meios e Mídias: Dualidades Complementares 105

2.3 Meios e Mediações: Confluências e Extensões 106

2.4 Da Cultura das Mídias à Cultura dos Meios $\quad \mathbf{1 0 8}$

2.5 Convergência de Mídias versus Convergência de Meios 109

2.6 A Mídia Digital e Seus Meios 11

2.7 Dos Meios de Leitura à Leitura dos Meios 112

$\begin{array}{ll}\text { CAPÍTULO III } & 117\end{array}$

\section{DA TEORIA DA MEDIAÇÃO: DIMENSÕES}

\section{HUMANAS}

3.1 Do conhecimento do Mundo ao Mundo do Conhecimento 119

3.2 Cognição e Mediações

3.3 Complexidade e Mediações $\quad \mathbf{1 2 8}$

3.4 Inteligência e Mediações $\quad \mathbf{1 3 0}$

3.5 Sentido e Mediações 134

$\begin{array}{ll}\text { 3.6 Linguagens, Tecnologias e Mediações } & 137\end{array}$

3.7 Imagens e Mediações

3.8 Metáforas Mediações 142

CAPÍTULO IV 145

DA TEORIA DA MEDIAÇÃO À TEORIA DOS MEIOS DIGITAIS

4.1 A Transformação dos Aportes Conceituais Mediativos $\mathbf{1 4 6}$

4.2 Artefatos Tecnológicos e Consciência Crítica 148 
4.3 Hibridações Conceituais e Outras Formas de Conhecimentos

\section{A FORMAÇÃO DE PROFESSORES NA ERA DAS}

\section{REDES}

5.1 A Interface entre Midiologia, Hermenêutica e Educação no

Mundo Digital

5.2 A Leitura do Mundo Digital no Espaço Escolar: Pressupostos

Mediativos

5.3 Educando na Era das Redes: Sensibilidade Hipertextual e Outros

172

Modos de Ler Conhecimentos

5.4 Mediações Interagentes nos Meios Digitais

174

5.5 Meios, Mediações e Valores Educacionais

179

CAPÍTULO VI

183

\section{A EPISTEMOLOGIA DA LEITURA EM}

\section{CONTEXTOS TEÓRICO-PRÁTICOS DA}

\section{DIMENSÃO DIDÁTICA}

6.1 Análise Contextualizada de Processos Mediativos 185

6.1.1 Atividades com Alunos de Graduação, Pós-Graduação e $\quad \mathbf{1 8 6}$ Grupo de Pesquisa

6.1.2 Entrevistas com Pesquisadores $\mathbf{2 1 3}$

6.2 Estudo de Caso 
6.2.1 Interconexões entre as Idéias de Jacob Bronowski e James

Burke no Campo Pedagógico

6.2.2 Mídias e Leituras Inventariáveis na Perspectiva de James Burke

6.2.3 Apresentação do K-Web (Instituto James Burke)

243

6.2.4 Apresentação do STEA (NEA-FE/USP)

253

6.2.5 K-Web e STEA: Leituras e Itinerários Interpretativos

272

CAPÍTULO VII

285

\section{CONSIDERAÇÕES FINAIS}

\section{VIII - FONTES REFERENCIAIS}

A-) EPISTEMOLOGIA DA LEITURA

302

B-) TEORIA DA MEDIAÇÃO

305

C-) TEORIA DOS MEIOS DIGITAIS

307

D-) TEORIA HERMENÊUTICA

310

E-) FORMAÇÃO DE PROFESSORES

311

F-) ESTUDO DE CASO: BRONOWSKI e BURKE

314

G-) MÍDIAS DIGITAIS

315

H-) BIBLIOGRAFIA COMPLEMENTAR

315

\section{IX - ANEXOS}

ANEXO A - FÓRUM I (GRADUANDOS EM PEDAGOGIA)

ANEXO B - FÓRUM II (PROFESSORES EM FORMAÇÃO)

331

ANEXO C - FÓRUM III (PÓS-GRADUANDOS)

ANEXO D - FÓRUM IV (PESQUISADORES EM FORMAÇÃO)

ANEXO E - ROTEIRO DE ENTREVISTAS (Entrevista com James Burke via e-mail) 
(via e-mail)

ANEXO G - REFERÊNCIAS BIOBIBLIOGRÁFICAS 